\title{
Effects of functional training on strength, function level, and quality of life of persons in intensive care units
}

\author{
Byul Seo ${ }^{a}$, Won-Seob Shin ${ }^{a, b}$ \\ ${ }^{a}$ Department of Physical Therapy, Graduate School of Health and Medical, Daejeon University, Daejeon, Republic of Korea \\ ${ }^{\mathrm{b}}$ Department of Physical Therapy, College of Health and Medical Science, Daejeon University, Daejeon, Republic of Korea
}

\begin{abstract}
Objective: The purpose of this study was to investigate the effect of exercise therapy and bedside ergometer exercise on muscle strength, function level, and quality of life of persons in intensive care.

Design: Randomized Controlled Trial

Methods: Sixteen patients in the ICU were randomly assigned to either the exercise group $(n=8)$ or the bedside cycle ergometer group $(n=8)$. Activities in the ICU exercise group (rolling, sitting at the edge of the bed, transfer from sitting to standing, standing balance training, ambulation) and bedside cycle ergometer group were performed 5 times a week for 30 minutes during the ICU admission period. Medical Research Council (MRC) and Functional Status Scale-Intensive Care Unit (FSS-ICU) parameters were assessed at the time of admission to the ICU, and reevaluation was assessed on the day of ICU discharge. The Short Form-36 (SF-36) was assessed at the time of discharge from the ICU.

Results: MRC and FSS-ICU were significantly increased before and after intervention in both the experimental and control groups $(p<0.05)$. There was a significant difference between MRC and FSS-ICU in the comparison of the changes before and after the intervention $(p<0.05)$. SF-36 was compared between groups after intervention and there was a significant difference between the experimental and the control group $(p<0.05)$.

Conclusions: Muscle strength and functional levels improved after intervention in both the experimental and control groups. The ICU exercise group was more effective than the bedside cycle ergometer group to improve muscle strength, functional level, and quality of life performance of persons in the ICU.
\end{abstract}

Key Words: Exercise, Intensive care units, Muscle strength, Quality of life, Rehabilitation

\section{Introduction}

In the 2012 issue of Society of Critical Care Medicine, the concept of 'Post Intensive Care Syndrome' was proposed to affect the cognitive, physical, and mental health of persons in the Intensive Care Unit (ICU) and their families after discharge $[1,2]$. Long-term hospital stay in the ICU may lead to complications, such as deterioration, muscle atrophy, dyspnea, depression, and generation of fear, which degrades the quality of life related to health $[3,4]$. There has been a $5 \%$ to $10 \%$ increase in the ratio of long-term bed rest for severe chronic diseases in the ICU $[5,6]$. Persons in the ICU exhibit muscular dysfunction due to corticosteroids, muscle relaxants, and neuromuscular blockers used for inactivity and inflammation [7,8]. In addition, muscle weakness was most prominent during the second to third week of ICU stay. Patients who were expected to have bed rest for as long as possible should avoid premature muscle weakness and muscle loss [9]. The European Respiratory Society and the European Intensive Care Medicine Association recommend that active and passive exercises be initiated early in the ICU [9].

In order to prevent or reduce neuromuscular complications with physical therapy, it is necessary to perform passive upper and lower extremity range of motion exercises,

Received: 3 May, 2019 Revised: 4 June, 2019 Accepted: 7 June, 2019

Corresponding author: Won-Seob Shin (ORCID https://orcid.org/0000-0002-6515-7020)

Department of Physical Therapy, College of Health and Medical Science, Daejeon University, 62 Daehak-ro, Dong-gu, Daejeon 34520, Republic of Korea Tel: 82-42-280-2294 Fax: 82-42-280-2295 E-mail: shinws@dju.kr

(a) This is an Open-Access article distributed under the terms of the Creative Commons Attribution Non-Commercial License (http://creativecommons.org/licenses/ by-nc/4.0) which permits unrestricted non-commercial use, distribution, and reproduction in any medium, provided the original work is properly cited.

Copyright (๑ 2019 Korean Academy of Physical Therapy Rehabilitation Science 
postural exercises, muscle strengthening exercises, standing, and walking $[10,11]$. Domestic and international research has shown the effects of respiratory physiotherapy for patients admitted to the ICU and the evaluation of clinical physical therapy for patients in the ICU and found that step-by-step exercises and movements in the ICU were among many relevant respiratory-based physical therapy interventions $[12,13]$.

However, studies on Intensive Care Unit Acquired Weakness (ICUAW) are increasing domestically, but there is not much intervention for prevention and treatment of ICUAW. The diagnosis of ICUAW considers of preventive treatment [14], and the limb circumference and limb muscle area of the ICU patients [15]. However, there is a lack of research on preventive, functional, and exercise treatment for the occurrence of ICUAW and related factors in persons in the ICU.

The purpose of this study was to investigate the effects of muscle strength and functional training before and after applying exercise therapy and bedside ergometer exercise in persons in ICU, and to identify its effects on the quality of life after ICU discharge.

\section{Methods}

\section{Participants}

The subjects of this study were 16 persons admitted to the ICU in Chungnam National University Hospital in Daejeon who fully understood and agreed to exercise therapy and bedside ergometer exercises. The criteria for selecting the subjects were as follows: those who were communicative, had no contractures or limitations of the upper limb joints, were in the ICU for at least 5 days, and those who were able to walk independently before admission to the ICU. The exclusion criteria included those with chronic respiratory failure before admission to the ICU, damage to the leg, pelvis, and back, trauma surgery, severe pressure ulceration, neurological diseases affecting muscle strength, and finally, those who had signed a do not resuscitate consent form.

All procedures and methods of this study have been approved by the Institutional Review Board of Chung Nam National University Hospital (IRB No. CNUH 2017-05028) and follow the principles outlined in the Declaration of Helsinki.

\section{Procedure}

The subjects were randomly divided into two groups, with 8 subjects in the exercise therapy group and 8 subjects in the bedside ergometer exercise group (Figure 1).

Exercise therapy consisted of postural and passive or active exercises. Exercise interventions such as strength, postural, balance, and gait training were performed on the subjects [16]. The interventions were conducted by a physiotherapist from the ICU physical therapy department, and the intervention period was during the ICU admission period; the number of interventions was recorded for each subject. Types of functional training included: (1) rolling, (2) sit to stand training, (3) sitting on the end of the bed, (4) standing starting from a sitting position, and (5) dynamic sitting posture balance training/dynamic postural balance training, and (7) gait (Figure 2). The subject began with active range of motion exercises and functional training in supine position and proceeded gradually according to the subject's condition. The exercises consisted of progressive strengthening exercises, movement in bed after stretching, rolling in bed, standing up from the sitting position, and postural alignment while sitting on the end of the bed.

The bedside ergometer exercises (Figure 3 ) included endurance and strength training, and the subject was instructed to perform passive, active assisted exercise, or active exercises. The intervention period was conducted during the ICU admission period and the number of interventions per was recorded. The control group received a bedside ergometer exercise program for five days a week and used a MOTOmedLetto 2 (Reck-Technik GmbH \& Co. KG, Betzenweiler, Germany). This equipment can be operated passively or actively and can adjust the resistance level during active exercise. The goal of each exercise time was a personally adjusted intensity for 30 minutes. Those who received sedation were to perform passive exercise for 30 minutes. When the patient was able to exercise, they would proceed in two 15-minute sessions with a resting period in between. The exercise intensity was assessed at every exercise session and resistance was increased by one increment depending on the condition of the subject [17]. The intervention period was five times a week during the hospital stay in the ICU.

\section{Outcome measures}

\section{Muscle strength}

The Medical Research Council (MRC) is commonly used as a measurement tool to assess muscle strength within the ICU. MRC evaluates the deltoid, biceps, and wrist extensor muscles of the upper limb, and the hip flexor, quadriceps, and anterior tibial muscles of the lower limbs. Both the upper and lower limb muscles were assessed and reevaluated 


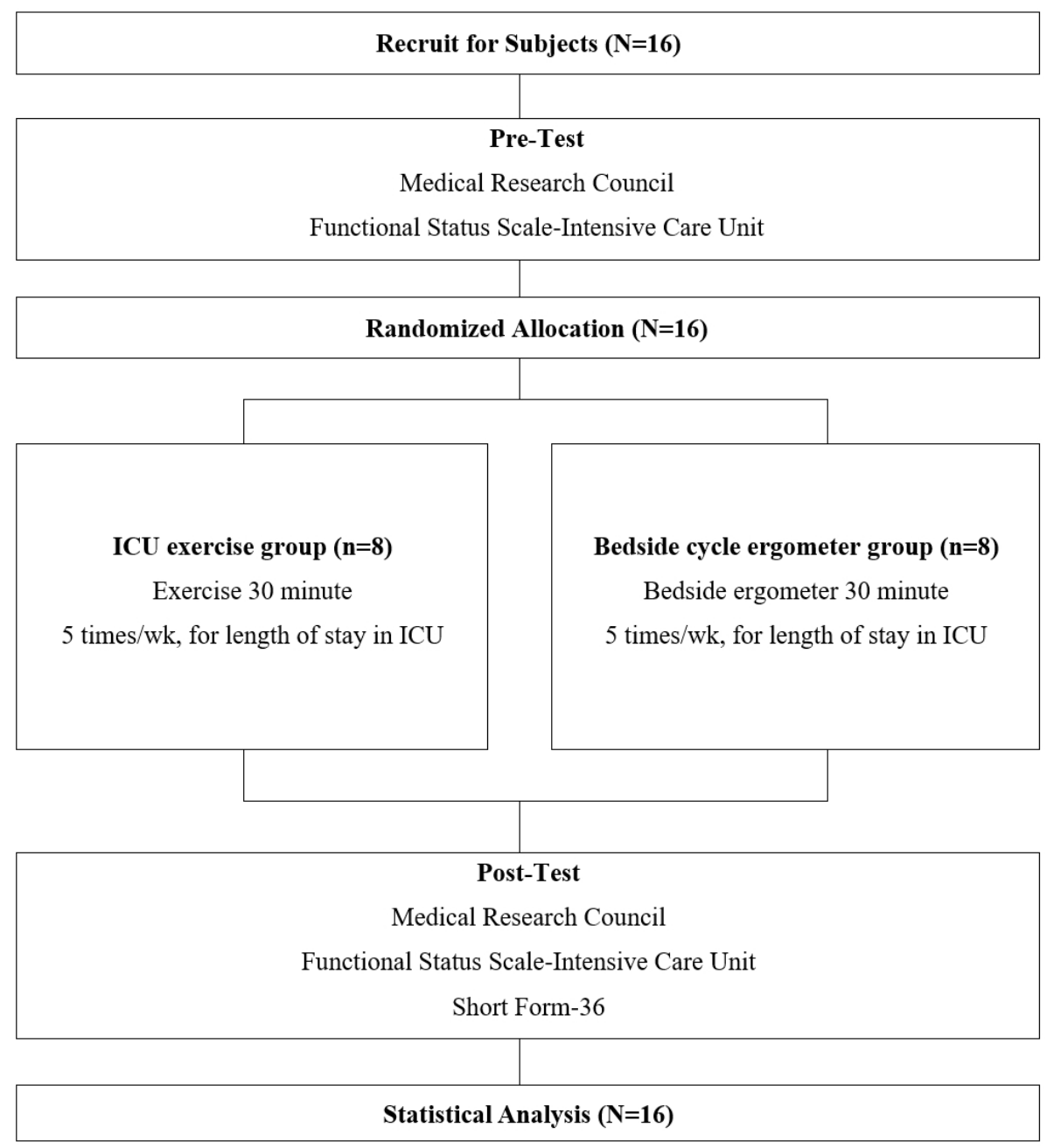

Figure 1. Flowchart of participants through the trial. ICU: Intensive Care Unit.

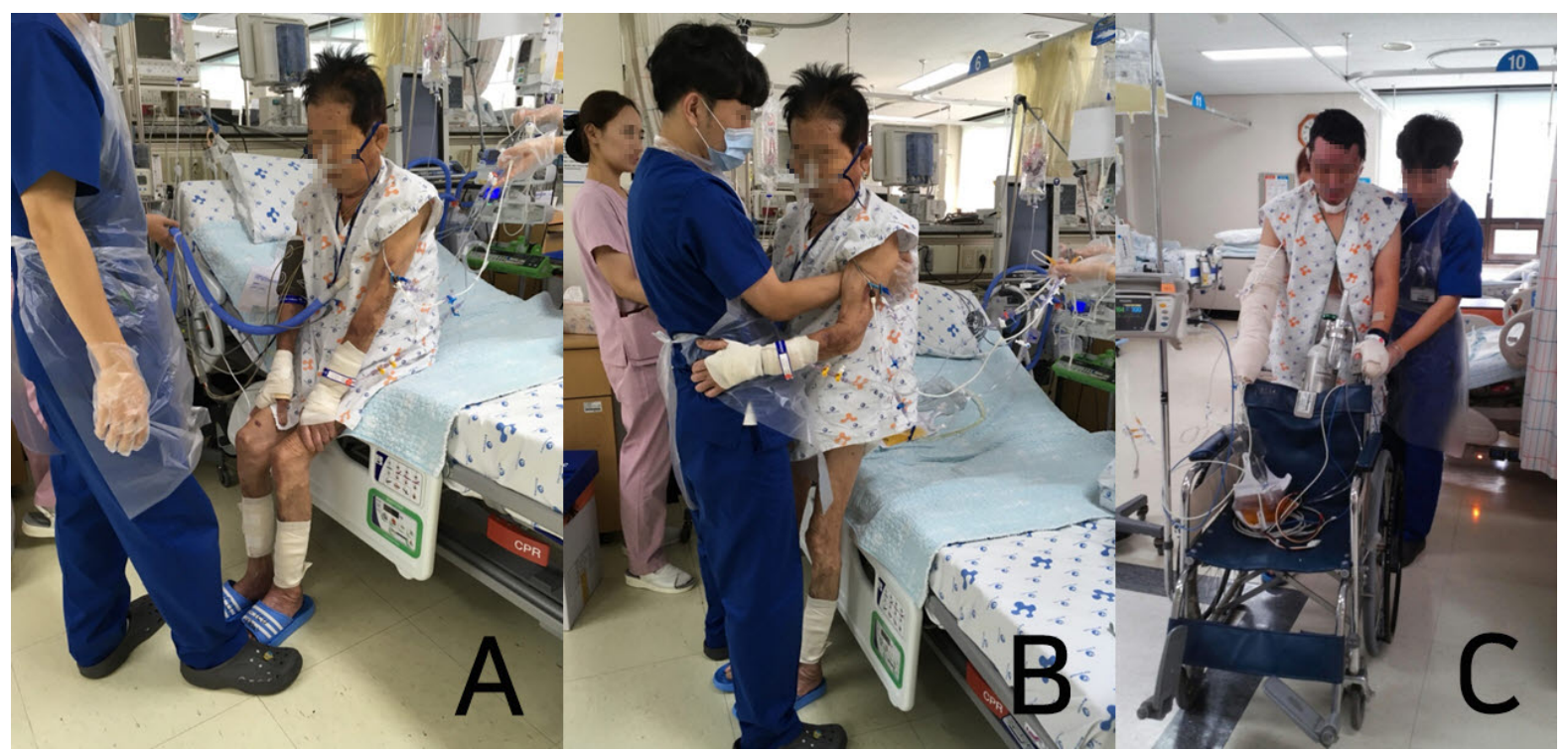

Figure 2. Intensive Care Unit exercise. (A) Dynamic sitting balance training (B) transfer from sit to stand. (C) Ambulation. 


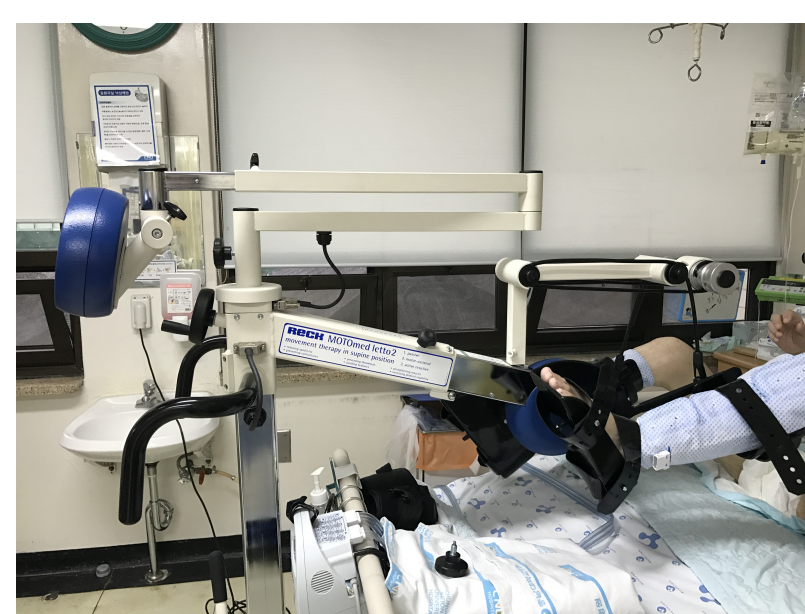

Figure 3. Bedside cycle ergometer.

before and after the intervention. The score is evaluated from 0 to 5 points and consists of a total of 60 points. A 0 point indicates no muscle contraction, 1 point indicates motion but no muscle contraction, 2 points indicate full motion range without gravity, 3 points indicate gravity full motion range, 4 points indicates moderate resistance, range of motion, and 5 points indicate normal muscle strength [18].

\section{Functional level}

The Functional Status Scale-Intensive Care Unit was developed to assess the functional levels in the ICU environment. The items are divided into a pre-walking item and a walking item. The pre-gait items can be carried out on the bed, rolling, sitting in the lying position, sitting without support, and the gait items consist of standing and standing from the sitting position as a functional movement out of the bed. The functional level evaluation consists of 5 items. A 0 point indicates it is not possible, 1 point indicates fully assisted, 2 points indicate maximum possible, 3 points indicate moderate, 4 points indicate minimum. If possible, 5 point can be assessed as possible if supervision is possible, 6 points indicate modified independence, 7 points will be assessed as completely independent if possible, score is 8 point points, minimum 0 point to maximum 35 points. The higher scores indicate higher level of performance of the subject [19].

\section{Quality of life}

The Short Form-36 consists of 8 domains: physical functioning, social functioning, role limitation due to physical health problem, role limitation due to emotional problems, general mental health, vitality, bodily pain, and general health [20].
Table 1. General characteristics of subjects

$(\mathrm{N}=16)$

\begin{tabular}{lccr}
\hline \multicolumn{1}{c}{ Characteristic } & $\begin{array}{c}\text { ICU exercise } \\
\text { group }(\mathrm{n}=8)\end{array}$ & $\begin{array}{c}\text { Bedside cycle } \\
\text { ergometer group } \\
(\mathrm{n}=8)\end{array}$ & $\chi^{2} / \mathrm{F}$ \\
\hline Sex (male/female) & $6 / 2$ & $3 / 5$ & 0.617 \\
Age (y) & $67.37(10.82)$ & $66.50(8.66)$ & 0.178 \\
APACHE & $21.25(3.10)$ & $21.87(5.38)$ & -0.284 \\
ICU length of stay & $22.37(8.86)$ & $24.00(4.27)$ & -0.467 \\
$\begin{array}{l}\text { Mechanical ventilator } \\
\text { duration }\end{array}$ & $14.50(7.23)$ & $13.50(4.10)$ & 1.213 \\
\hline
\end{tabular}

Values are presented as number only or mean (SD).

ICU: Intensive Care Unit, APACHE: Acute Physilolgy and Chronic Health Evaluation.

\section{Data and statistical analysis}

Data collected in this study were analyzed using PASW Statistics for Windows, Version 18.0 (SPSS Inc., Chicago, IL, USA). The general characteristics of the subjects were presented as mean and standard deviation by descriptive statistics. Chi-square test and independent sample t-test were performed to evaluate homogeneity in the exercise and bedside ergometer group. The Wilcoxon signed rank test was used to analyze changes in muscle strength and functional assessment indices before and after treatment in each group. The Mann-Whitney U-test was used to assess groupto-group differences in muscle strength, functional motion, and quality of life. The significance level was set at $p<0.05$.

\section{Results}

A total of 16 subjects participated in the study. The results were not statistically significant in age, sex, Acute Physiology and Chronic Health Evaluation, ICU length of stay, and mechanical ventilator duration between the two groups $(p>0.05)$. The general characteristics of the subjects are shown in Table 1.

There was a significant increase in muscle strength in both the experimental group $(p<0.05)$ and the control $(p<0.05)$. There was a significant difference between the two groups in terms of the changes before and after intervention $(p<0.05)$ (Table 2).

There was a significant increase in functional level in both experimental and control groups $(p<0.05)$. There was a significant difference between the two groups $(p<0.05)$ (Table 2$)$.

The quality of life was compared between the experimental and the control group after intervention. In the ex- 
Table 2. Comparative analysis of MRC and FSS-ICU $\quad(\mathrm{N}=16)$

\begin{tabular}{lccc}
\hline Variable & $\begin{array}{c}\text { ICU exercise } \\
\text { group }(\mathrm{n}=8)\end{array}$ & $\begin{array}{c}\text { Bedside cycle } \\
\text { ergometer group } \\
(\mathrm{n}=8)\end{array}$ & $\mathrm{Z}(p)^{\mathrm{a}}$ \\
\hline MRC & & & \\
Pre & $34.75(9.14)$ & $34.75(6.01)$ & $-0.106(0.916)$ \\
Post & $45.62(4.34)$ & $39.75(6.29)$ & $-1.835(0.067)$ \\
Change & $10.87(7.14)$ & $5.00(1.69)$ & $-2.042(0.041)$ \\
$\mathrm{Z}(p)^{\mathrm{b}}$ & $-2.375(0.018)$ & $-2.565(0.010)$ & \\
FSS-ICU & & & \\
Pre & $11.00(4.84)$ & $10.50(3.96)$ & $-0.317(0.751)$ \\
Post & $17.12(6.24)$ & $12.12(4.12)$ & $-1.640(0.101)$ \\
Change & $6.12(2.58)$ & $1.62(1.06)$ & $-3.196(0.001)$ \\
Z $(p)^{\mathrm{b}}$ & $-2.536(0.011)$ & $-2.392(0.017)$ & \\
\hline
\end{tabular}

Values are presented as mean (SD).

ICU: Intensive Care Unit, MRC: Medical Research Council, FSS-ICU: Functional Status Scale-Intensive Care Unit.

${ }^{\mathrm{a}}$ Mann-Whitney U test. ${ }^{\mathrm{b}}$ Wilcoxon signed rank test.

perimental and the control group, social functioning, role limitation due to physical health problems, role limitation due to emotional problems, general mental health, vitality, pain, general health and quality of life were significantly different after intervention $(p<0.05)$ (Table 3$)$.

\section{Discussion}

Subjects in the ICU suffered from cognitive, physical, and mental health problems for a month or a year after discharge. Physical health-related problems included weakness in mobility, reduction in bed activity, decreased ability to walk, and mental health problems, such as anxiety and depression [5]. This is a case of ICUAW, which can be explained by critical illness myopathy, critical illness polyneuropathy and myopathy, and critical illness polyneuropathy [21]. Severe disease muscle neuropathy is characterized by changes in muscle and sensory nerves, and severe myopathy is characterized by limb paralysis [22]. Muscle weakness and dysfunction were reported in $25 \%$ of ICU patients [23], and the development of management of mechanical ventilation improved patient outcomes and survival [24]. Muscle weakness and dysfunction cause further complications and are associated with dysfunction and long-term rehabilitation $[2,6]$. The muscular atrophy process begins within 72 hours and may be associated with loss of muscle mass and muscle loss within 10 days after bed rest in healthy and nutritious muscles [22]. Interventions aimed at improving functional recovery may not only minimize or improve physical func-
Table 3. Comparative analysis of SF-36 after intervention $(\mathrm{N}=16)$

\begin{tabular}{llll}
\hline Variable & $\begin{array}{c}\text { ICU exercise } \\
\text { group }(\mathrm{n}=8)\end{array}$ & $\begin{array}{c}\text { Bedside cycle } \\
\text { ergometer group } \\
(\mathrm{n}=8)\end{array}$ & $\mathrm{Z}(p)$ \\
\hline PF & $60.62(27.18)$ & $36.87(8.42)$ & $-1.748(0.080)$ \\
SF & $71.25(5.66)$ & $39.06(10.43)$ & $-3.437(0.001)$ \\
RL PHP & $68.75(22.16)$ & $34.37(12.93)$ & $-2.902(0.004)$ \\
RL EP & $95.83(11.77)$ & $37.47(11.80)$ & $-3.623(<0.001)$ \\
GMH & $67.50(7.83)$ & $46.50(9.54)$ & $-2.976(0.003)$ \\
Vitality & $66.25(6.94)$ & $41.25(5.82)$ & $-3.403(0.001)$ \\
Bodily pain & $76.25(7.55)$ & $50.93(5.65)$ & $-3.467(0.001)$ \\
GH & $63.12(9.23)$ & $42.50(5.97)$ & $-3.184(0.001)$ \\
Total score & $71.19(7.93)$ & $41.11(5.02)$ & $-3.363(0.001)$ \\
\hline
\end{tabular}

Values are presented as mean (SD).

SF-36: Short Form-36, ICU: Intensive Care Unit, PF: physical functioning, SF: social functioning, RL PHP: role limitation due to a physical health problem, RL EP: role limitation due to emotional problems, GMH: general mental health, GH: general health.

tion, but may also affect cognitive processes and emotional health. Therefore, measurements that evaluate these aspects should be investigated at various points in time [23]. It is recommended that interventions for rehabilitation treatment of ICUs should be implemented early in order to reduce the duration of ICU length of stay and to prevent complications in the ICU [9]. The purpose of this study was to investigate the effect of exercise therapy and bedside ergometer exercise on muscle strength, function level, and quality of life of persons in the ICU. Positive effects on strength, functional level, and quality of life were confirmed through interventions during the subject's stay in the ICU.

In the ICU, muscular strength and muscle endurance were influenced by exercise therapy and bedside ergometer exercises. This trial shows that both muscle strength and functional level outcomes of persons with critical illness on mechanical ventilation can be improved by the implementation of exercise therapy and bedside ergometer exercise [22]. The reason why there was a significant difference in muscle strength in the functional training group was that the dynamic and functional training intervention also affected muscle strength. There was a significant difference between the exercise group and the general treatment group in correlation to maximum walking distance with improvement of muscle strength [23]. Bridge exercise performance as a bed mobility exercise can strengthen the hip and trunk muscles, and trunk muscle training affects the core muscles [25]. Improvement of walking speed and balance ability and functional ability occurs by strengthening the hip muscles [26]. 
There is an increasing interest in assessing the level of physical functioning of severely ill patients and studies are being conducted to evaluate ICU-based interventions that can reduce these disorders [27-29]. In the exercise group, functional training, such as bedside functional training, balance training, and gait training assisted to improve physical performance or functional level [29]. Active functional training and rehabilitation in the ICU is consistent with research that improves functional levels, reduces movement restrictions, and improves muscle strength and gait ability [27]. Exercise improves cardiopulmonary endurance by strengthening postural control muscles and inspiratory muscle strength [30].

Persons with psychological disturbances such as depression, anxiety, and fear may also experience physical disabilities in the ICU [1]. Patients after ICU discharge are more likely to have anxiety and depression, higher dependence, and lower quality of life due to psychological related quality of life and health related quality of life [31]. There was a significant difference in the quality of life between the two groups in the ICU. It is consistent with the study that the quality of life was improved by improving muscle strength, functional training and gait training.

The factors affecting the quality of life after ICU discharge were physical strength, functional level, and physical activity level. Therefore, a gradual exercise program intervention is needed [12].

As a result of this study, the following limitations were noted: First, it consisted of patients who could cooperate with exercise therapy. Thus, these findings have limited application for all persons in the ICU. Second, a prospective screening for the presence of critical illness or neuromuscular abnormalities in all subjects was not performed.

\section{Conflict of Interest}

The authors declared no potential conflicts of interest with respect to the authorship and/or publication of this article.

\section{References}

1. Schweickert WD, Gehlbach BK, Pohlman AS, Hall JB, Kress JP. Daily interruption of sedative infusions and complications of critical illness in mechanically ventilated patients. Crit Care Med 2004;32:1272-6.

2. Martin UJ, Hincapie L, Nimchuk M, Gaughan J, Criner GJ. Impact of whole-body rehabilitation in patients receiving chron- ic mechanical ventilation. Crit Care Med 2005;33:2259-65.

3. Combes A, Costa MA, Trouillet JL, Baudot J, Mokhtari M, Gibert $\mathrm{C}$, et al. Morbidity, mortality, and quality-of-life outcomes of patients requiring $>$ or $=14$ days of mechanical ventilation. Crit Care Med 2003;31:1373-81.

4. Herridge MS, Cheung AM, Tansey CM, Matte-Martyn A, Diaz-Granados N, Al-Saidi F, et al. One-year outcomes in survivors of the acute respiratory distress syndrome. N Engl J Med 2003;348:683-93.

5. Fletcher SN, Kennedy DD, Ghosh IR, Misra VP, Kiff K, Coakley $\mathrm{JH}$, et al. Persistent neuromuscular and neurophysiologic abnormalities in long-term survivors of prolonged critical illness. Crit Care Med 2003;31:1012-6.

6. Carson SS, Bach PB, Brzozowski L, Leff A. Outcomes after long-term acute care. An analysis of 133 mechanically ventilated patients. Am J Respir Crit Care Med 1999;159(5 Pt 1):1568-73.

7. Topp R, Ditmyer M, King K, Doherty K, Hornyak J 3rd. The effect of bed rest and potential of prehabilitation on patients in the intensive care unit. AACN Clin Issues 2002;13:263-76.

8. De Jonghe B, Lacherade JC, Durand MC, Sharshar T. Critical illness neuromuscular syndromes. Neurol Clin 2008;26:507-20, ix.

9. Gruther W, Benesch T, Zorn C, Paternostro-Sluga T, Quittan M, Fialka-Moser V, et al. Muscle wasting in intensive care patients: ultrasound observation of the M. quadriceps femoris muscle layer. J Rehabil Med 2008;40:185-9.

10. Gosselink R, Bott J, Johnson M, Dean E, Nava S, Norrenberg M, et al. Physiotherapy for adult patients with critical illness: recommendations of the European Respiratory Society and European Society of Intensive Care Medicine Task Force on Physiotherapy for Critically Ill Patients. Intensive Care Med 2008;34:1188-99.

11. Morris PE. Moving our critically ill patients: mobility barriers and benefits. Crit Care Clin 2007;23:1-20.

12. Stiller K. Physiotherapy in intensive care: towards an evidence-based practice. Chest 2000;118:1801-13.

13. Chaboyer W, Gass E, Foster M. Patterns of chest physiotherapy in Australian Intensive Care Units. J Crit Care 2004;19:145-51.

14. Kwon KH, Min YK. Intensive care unit-acquired weakness. J Korean Assoc EMG Electrodiagn Med 2013;15:64-72.

15. Hwang YH, Choe MA. Study on the changes in limb circumferences and muscle areas of critically Ill patients using ventilators. J Korean Acad Nurs 2008;38:874-80.

16. Norrenberg M, Vincent JL. A profile of European intensive care unit physiotherapists. European Society of Intensive Care Medicine. Intensive Care Med 2000;26:988-94.

17. Burtin C, Clerckx B, Robbeets C, Ferdinande P, Langer D, Troosters $\mathrm{T}$, et al. Early exercise in critically ill patients enhances short-term functional recovery. Crit Care Med 2009;37:2499505.

18. Hough CL, Lieu BK, Caldwell ES. Manual muscle strength testing of critically ill patients: feasibility and interobserver agreement. Crit Care 2011;15:R43.

19. Thrush A, Rozek M, Dekerlegand JL. The clinical utility of the functional status score for the intensive care unit (FSS-ICU) at a long-term acute care hospital: a prospective cohort study. Phys Ther 2012;92:1536-45.

20. Aaronson NK, Muller M, Cohen PD, Essink-Bot ML, Fekkes M, Sanderman R, et al. Translation, validation, and norming of the 
Dutch language version of the SF-36 Health Survey in community and chronic disease populations. J Clin Epidemiol 1998;51: 1055-68

21. Kortebein P, Ferrando A, Lombeida J, Wolfe R, Evans WJ. Effect of 10 days of bed rest on skeletal muscle in healthy older adults. JAMA 2007;297:1772-4.

22. Schweickert WD, Pohlman MC, Pohlman AS, Nigos C, Pawlik AJ, Esbrook CL, et al. Early physical and occupational therapy in mechanically ventilated, critically ill patients: a randomised controlled trial. Lancet 2009;373:1874-82.

23. Hodgson C, Needham D, Haines K, Bailey M, Ward A, Harrold $\mathrm{M}$, et al. Feasibility and inter-rater reliability of the ICU Mobility Scale. Heart Lung 2014;43:19-24.

24. Hwang JY, Ahn WY, Kim HJ, Woo JH, Choi WJ, Park JW, et al. Effects of performing hip abduction and adduction during bridging exercise on trunk and lower extremity muscle activity in healthy individuals. Phys Ther Rehabil Sci 2017;6:14-9.

25. Jung DK, Chung YJ. The effect of hip joint strengthening exercise using proprioceptive neuromuscular facilitation on balance, sit to stand and walking ability in a person with traumatic brain injury: a case report. Phys Ther Rehabil Sci 2017;6:96-104. 26. Tipping CJ, Young PJ, Romero L, Saxena MK, Dulhunty J, Hodgson CL. A systematic review of measurements of physical function in critically ill adults. Crit Care Resusc 2012;14:302-11.

27. Parry SM, Denehy L, Beach LJ, Berney S, Williamson HC, Granger CL. Functional outcomes in ICU - what should we be using? - an observational study. Crit Care 2015;19:127.

28. Connolly B. Describing and measuring recovery and rehabilitation after critical illness. Curr Opin Crit Care 2015;21:445-52.

29. An SK, Shin WS. Effect of air stacking training on pulmonary function, respiratory strength and peak cough flow in persons with cervical spinal cord injury. Phys Ther Rehabil Sci 2018;7: 147-53.

30. Griffiths RD. Effect of passive stretching on the wasting of muscle in the critically ill: background. Nutrition 1997;13:70-4.

31. Mehrholz J, Thomas S, Burridge JH, Schmidt A, Scheffler B, Schellin R, et al. Fitness and mobility training in patients with Intensive Care Unit-acquired muscle weakness (FITonICU): study protocol for a randomised controlled trial. Trials 2016; 17:559. 